\title{
The impact of current smoking, regular drinking, and physical inactivity on health care- seeking behavior in China
}

\author{
Changle Li and Jing Sun ${ }^{*}$
}

\begin{abstract}
Background: People with lifestyle behaviors, such as current smoking, regular drinking, and physical inactivity, may experience a lack of or delayed health care, leading to severe sickness and higher health care expenditures in the future. Hence, the current study aims to ascertain the effects of current smoking, regular drinking, and physical inactivity on health care-seeking behavior among adults who report physical discomfort in China.

Methods: The data used in this study were obtained from the China Family Panel Studies (CFPS). The final sample consisted of 44,362 individuals who participated in all five waves of data collection. Logistic regression models were used for the analysis.

Results: The results of fixed effects logistic regression showed that among those who reported physical discomfort, adults who currently smoked cigarettes were 0.65 times less likely to seek health care than those who formerly smoked. Compared to nondrinkers, adults who regularly drank alcohol had a decreased likelihood of seeking health care. Adults who never engaged in physical exercise had $24 \%$ lower odds of seeking health care than those who engaged in physical exercise.

Conclusions: Current smoking, regular drinking, and physical inactivity decreased the probability of seeking health care among adults who reported physical discomfort. Therefore, screening and brief advice programs should be delivered by primary-level care and should pay more attention to individuals who engage in lifestyle behaviors such as current smoking, regular drinking, and physical inactivity, thus avoiding missed opportunities to treat chronic conditions and detect new diseases early.
\end{abstract}

Keywords: Lifestyle, Smoking, Regular drinking, Physical inactivity, Health care-seeking behavior

\section{Background}

In 2015, a Chinese national nutrition and chronic disease report indicated that the prevalences of current smoking, harmful drinking, and physical inactivity among adults were $28.1,9.3$, and $71.3 \%$, respectively [1]; these preventable risk factors have contributed to the increased rise in chronic diseases. Chronic diseases now account for

*Correspondence: sunjing@immu.edu.cn

School of Health Management, Inner Mongolia Medical University, Hohhot 010110, China approximately $80 \%$ of total deaths and $70 \%$ of total disability-adjusted life years lost in China [2].

Lifestyles have proven to be independent or synergistical causes of diseases, such as hypertension, dyslipidemia, diabetes, and obesity [3]. Most people make lifestyle changes due to the health concerns and illnesses they experience. For example, in 2018, 38.7\% of Chinese smokers stopped smoking because they were worried about their future health status, and $26.6 \%$ stopped smoking because they experienced severe sickness [4]. In addition, former smoking has been associated with higher health 
care utilization and increased health care expenditures [5-8]. People with lifestyle behaviors including current smoking, regular drinking, and physical inactivity may not care about their health status or may be risk-tolerant individuals. As a result, they may experience a lack of or delayed health care, thereby leading to severe sickness and higher health care expenditures in the future [9-11].

To our knowledge, little is known about the association between lifestyle factors and health care-seeking behavior $[12,13]$. Hence, the current study aims to ascertain the effects of current smoking, regular drinking, and physical inactivity on health care-seeking behavior among adults who report physical discomfort in China. This knowledge will help better understand the associations between current smoking, regular drinking, and physical inactivity and health care-seeking behavior, thus helping the government make health care resource allocation decisions and improve health education programs for target populations.

\section{Methods}

\section{Data source and study sample}

The data used in this study were obtained from the China Family Panel Studies (CFPS), conducted by the Institute of Social Science Survey of Peking University. The CFPS is a nationally representative, biennial survey designed to collect Chinese community-, family-, and individuallevel longitudinal data; the data cover twenty-five provinces and their administrative equivalents, representing approximately $95 \%$ of the total population in mainland China. The CFPS uses multistage probability proportional-to-size sampling. More details of the data collection process were given in Xie and $\mathrm{Lu}$ [14]. The CFPS questionnaires include questions on demographic background, family structure/transfer, health status and physical functioning, health care utilization, insurance status, work, income, expenditure, asset ownership, communitylevel information, etc. [15].

The CFPS primarily conducts face-to-face interviews. Telephone or online interviews are used as a substitute only when the CFPS fails to complete face-to-face interviews. In the first wave in 2010, 14,960 households, including 33,600 adults (above 16years old) and 8990 children, were successfully interviewed; in four waves of full sample follow-up surveys in 2012, 2014, 2016, and 2018, 13,315 households (35,720 adults and 8624 children), 13,946 households (37,147 adults and 8617 children), 14,019 households (36,892 adults and 8427 children), and 14,218 households (37,354 adults and 8735 children) were successfully interviewed, respectively. More details about the CFPS are available from Xie and $\mathrm{Hu}[16]$.
From the full sample, only the adults (16years old or older) who reported feeling any physical discomfort in the past 2 weeks prior to the survey interview were selected. The final sample consisted of 44,362 individuals who participated in all five waves of data collection.

\section{Measures \\ Dependent variable}

Health care-seeking behavior was set as a binary variable, indicating the decision to consult a doctor (or not) among the adults who reported feeling any physical discomfort in the past 2 weeks. The question in the CFPS that represent this variable is: 'Have you seen a doctor within the past two weeks?'. Response options are: Yes or no.

\section{Independent variables}

The respondents completed a face-to-face interview about lifestyle factors, including current smoking, regular drinking, and physical inactivity. In the CFPS, each respondent was asked, 'Have you smoked in the past month?'. A respondent reporting 'Yes' was categorized as current smoking. Respondents who reported 'No' were then asked, 'Have you ever smoked? Yes or No'. If the respondent reported 'Yes', the respondent was categorized as former smoking. If the respondent reported 'No' to both questions, the respondent was categorized as never smoking. Regular drinking was defined as a binary variable. The CFPS question supporting this variable was 'Have you often drunk alcohol (at least three times a week) in the past month?'. Respondents reporting 'Yes' were coded as 1, and those reporting 'No' were coded as 0 . In the CFPS, the respondents were asked how often they participated in physical exercise in the past week. The respondents were categorized as physical inactivity if they answered "Never".

The other independent variables were selected based on previous studies and included the respondent's age, gender, marital status, urban residency, household income, medical insurance status, educational attainment, employment status, self-reported health status, chronic conditions, and severity of physical discomfort (SPD). A single question was used to measured SPD, which was classified into three categories by asking the respondents how serious they thought their physical discomfort was: mild, moderate, or serious. Definitions of all relevant variables are provided in Table 1.

\section{Statistical analysis}

Bivariate analyses were used to examine differences between adults who consulted a doctor (seeking health care) and those who did not consult a doctor when they felt physical discomfort in each wave. Pearson's 
Table 1 Definitions of variables

\begin{tabular}{|c|c|}
\hline Variable & Description \\
\hline \multicolumn{2}{|l|}{ Dependent variable } \\
\hline Health care-seeking behavior & Coded: 1 if the individual self-reported consulting a doctor; 0 otherwise \\
\hline \multicolumn{2}{|l|}{ Independent variable } \\
\hline \multicolumn{2}{|l|}{ Smoking status } \\
\hline Current smoking & Coded: 1 if the individual currently smokes cigarettes; 0 otherwise \\
\hline Former smoking & Coded: 1 if the individual has quit smoking; 0 otherwise \\
\hline Never smoking & Coded: 1 if the individual has never smoked; 0 otherwise \\
\hline Regular drinking & Coded: 1 if the individual drank alcohol at least 3 times a week in past month; 0 otherwise \\
\hline Physical inactivity & Coded: 1 if the individual never participated in physical exercise in the past week; 0 otherwise \\
\hline \multicolumn{2}{|l|}{ Age group } \\
\hline $16-24$ & Coded: 1 if the individual is $16-24$ years old; 0 otherwise \\
\hline $25-64$ & Coded: 1 if the individual is $25-64$ years old; 0 otherwise \\
\hline$>=65$ & Coded: 1 if the individual is $>=65$ years old; 0 otherwise \\
\hline Male & Coded: 1 if the individual is male; 0 for female \\
\hline \multicolumn{2}{|l|}{ Educational attainment } \\
\hline Illiterate & Coded: 1 if the individual is illiterate; 0 otherwise \\
\hline Elementary school & Coded: 1 if the individual attends elementary school; 0 otherwise \\
\hline Middle school & Coded: 1 if the individual graduated from middle school; 0 otherwise \\
\hline High school & Coded: 1 if the individual graduated from high school; 0 otherwise \\
\hline Above three-year college & Coded: 1 if the individual graduated from above three-year college; 0 otherwise \\
\hline Married & Coded: 1 if the individual is married; 0 otherwise \\
\hline Urban residency & Coded: 1 if the individual is an urban resident; 0 for rural resident \\
\hline \multicolumn{2}{|l|}{ Medical insurance } \\
\hline GMl & Coded: 1 if the individual is enrolled in the Government Medical Insurance; 0 otherwise \\
\hline UEMI & Coded: 1 if the individual is enrolled in the Urban Employee Medical Insurance; 0 otherwise \\
\hline URMI & Coded: 1 if the individual is enrolled in the Urban Resident Medical Insurance; 0 otherwise \\
\hline NRCMI & Coded: 1 if the individual is enrolled in the New Rural Cooperative Medical Insurance; 0 otherwise \\
\hline Other Insurance & Coded: 1 if the individual is enrolled in supplementary medical insurance; 0 otherwise \\
\hline No Insurance & Coded: 1 if the individual does not have medical insurance; 0 otherwise \\
\hline Household income & Net household income (10,000 Yuan) \\
\hline Economically active & $\begin{array}{l}\text { Coded: } 1 \text { if the individual reports participating in agricultural jobs, working for wages for an employer, or working } \\
\text { for oneself rather than an employer; } 0 \text { if the individual reports being a temporary worker, retired, unemployed, or a } \\
\text { student; }\end{array}$ \\
\hline \multicolumn{2}{|l|}{ Health status } \\
\hline Poor & Coded: 1 if the individual reports his or her health status to be poor; 0 otherwise \\
\hline Fair & Coded: 1 if the individual reports his or her health status to be fair; 0 otherwise \\
\hline Good & Coded: 1 if the individual reports his or her health status to be good, very good, or excellent; 0 otherwise \\
\hline Chronic conditions & Coded: 1 if the individual has had doctor-diagnosed chronic diseases in the past 6 months; 0 otherwise \\
\hline \multicolumn{2}{|l|}{ Severity of physical discomfort } \\
\hline Mild & $\begin{array}{l}\text { Coded: } 1 \text { if the individual perceives himself or herself to have had mild physical discomfort in the past } 2 \text { weeks; } 0 \\
\text { otherwise }\end{array}$ \\
\hline Moderate & $\begin{array}{l}\text { Coded: } 1 \text { if the individual perceives himself or herself to have had moderate physical discomfort in the past } 2 \text { weeks; } \\
0 \text { otherwise }\end{array}$ \\
\hline Serious & $\begin{array}{l}\text { Coded: } 1 \text { if the individual perceives himself or herself to have had serious physical discomfort in the past } 2 \text { weeks; } 0 \\
\text { otherwise }\end{array}$ \\
\hline
\end{tabular}

chi-square test was used to analyze the categorical independent variables.

The current study examined the relationship between the dependent variable and independent variables using pooled and panel data estimation. Pooled estimation can increase the sample size, but it is often biased or at least inefficient [17]. Therefore, a pooled regression model can be a starting point. After the use of the pooled regression 
model, the data were treated as having a panel structure, and a choice between fixed and random effects models had to be made. The panel structure can increase the degrees of freedom and decrease the collinearity among independent variables. Based on Hausman's specification test, fixed effects estimation should be preferred over random effects estimation. However, when estimating the fixed effects model, many pieces of information are lost. Therefore, a random effects model was also presented in this study $[17,18]$.

Since the dependent variable was a binary response variable, logistic regression was used to examine the impact of current smoking, regular drinking, and physical inactivity on health care-seeking behavior in China. The final model was adjusted for all the confounding variables. The results are presented as odds ratios (ORs)

Table 2 Description of the selected variables in the five waves (percentage)

\begin{tabular}{|c|c|c|c|c|c|}
\hline & $\begin{array}{l}2010 \\
N=8358\end{array}$ & $\begin{array}{l}2012 \\
N=9061\end{array}$ & $\begin{array}{l}2014 \\
N=8774\end{array}$ & $\begin{array}{l}2016 \\
N=9021\end{array}$ & $\begin{array}{l}2018 \\
N=9148\end{array}$ \\
\hline Health care-seeking behavior & 68.8 & 65.4 & 72.3 & 74.9 & 76.1 \\
\hline Current smoking & 28.8 & 27.4 & 26.2 & 24.9 & 25.7 \\
\hline Former smoking & 7.3 & 5.0 & 5.2 & 5.2 & 8.2 \\
\hline Never smoking & 63.9 & 67.5 & 68.6 & 69.8 & 66.2 \\
\hline Regular drinking & 12.9 & 13.2 & 13.1 & 11.7 & 12.5 \\
\hline Physical inactivity & 72.0 & 56.9 & 63.2 & 58.8 & 52.8 \\
\hline \multicolumn{6}{|l|}{ Age group } \\
\hline $16-24$ & 6.8 & 7.4 & 6.4 & 7.3 & 6.4 \\
\hline $25-64$ & 76.0 & 74.5 & 73.7 & 70.9 & 69.9 \\
\hline$>=65$ & 17.2 & 18.2 & 20.0 & 21.8 & 23.7 \\
\hline Male & 42.7 & 43.4 & 42.3 & 42.0 & 42.8 \\
\hline \multicolumn{6}{|l|}{ Educational attainment } \\
\hline Illiteracy & 36.1 & 35.4 & 35.4 & 34.5 & 30.4 \\
\hline Elementary school & 21.5 & 21.6 & 22.2 & 21.5 & 21.6 \\
\hline Middle school & 25.0 & 23.8 & 24.4 & 24.4 & 26.1 \\
\hline High school & 11.8 & 12.4 & 11.7 & 11.7 & 12.5 \\
\hline Above three-year college & 5.7 & 6.8 & 6.3 & 8.0 & 9.5 \\
\hline Married & 82.5 & 82.5 & 82.3 & 80.4 & 79.9 \\
\hline Urban residency & 44.8 & 45.4 & 47.1 & 47.5 & 47.7 \\
\hline \multicolumn{6}{|l|}{ Medical insurance } \\
\hline GMI & 4.7 & 3.7 & 2.9 & 1.9 & 2.4 \\
\hline UEMI & 9.5 & 12.2 & 12.6 & 12.4 & 13.1 \\
\hline URMI & 7.0 & 7.6 & 8.2 & 8.0 & 7.9 \\
\hline NRCMI & 58.1 & 64.6 & 67.5 & 68.2 & 67.7 \\
\hline Other Insurance & 0.5 & 0.3 & 0.6 & 0.4 & 0.3 \\
\hline No Insurance & 20.2 & 11.7 & 8.2 & 9.1 & 8.6 \\
\hline Household income $^{a}$ & $3.3(5.3)$ & $4.2(5.0)$ & $4.6(6.1)$ & $5.4(12.5)$ & $5.6(8.5)$ \\
\hline Economically active & 45.4 & 67.5 & 71.5 & 75.3 & 73.2 \\
\hline \multicolumn{6}{|l|}{ Health status } \\
\hline Poor & 38.9 & 41.0 & 36.1 & 36.2 & 36.4 \\
\hline Fair & 42.0 & 23.0 & 19.5 & 22.6 & 16.7 \\
\hline Good & 19.1 & 36.0 & 44.4 & 41.3 & 46.9 \\
\hline Chronic conditions & 29.0 & 22.1 & 34.6 & 34.0 & 32.7 \\
\hline \multicolumn{6}{|l|}{ Severity of physical discomfort } \\
\hline Mild & 22.2 & 24.1 & 20.8 & 20.9 & 17.3 \\
\hline Moderate & 40.1 & 39.7 & 47.2 & 42.3 & 44.4 \\
\hline Serious & 37.7 & 36.2 & 32.0 & 36.8 & 38.4 \\
\hline
\end{tabular}

RMB: 1000 Chinese Renminbi is approximately 150 US\$

${ }^{\text {a }}$ Values are expressed as the mean (standard deviation) 
along with 95\% confidence intervals (CIs). All statistical analyses were carried out using the statistical software package STATA 15.

\section{Results}

A descriptive summary of all variables over time is shown in Table 2. Among those who reported physical discomfort, the proportion of people seeking health care increased from $68.8 \%$ in 2010 to $76.1 \%$ in 2018. Approximately $26.0 \%$ of adults currently smoked tobacco products from 2010 to 2018 . Approximately $12.0 \%$ of adults regularly drank alcohol from 2010 to 2018 . The prevalence of physical inactivity was $72.0 \%$ in 2010 . This proportion decreased to $52.8 \%$ in 2018 .

Table 3 compares adults who sought health care and those who did not seek health care when they felt physical discomfort based on a variety of lifestyle factors. Among those who reported physical discomfort, adults who currently smoked were less likely to seek health care, and a similar trend was observed for adults who regularly drank alcohol. In addition, the chi-square test found that current smoking and regular drinking were significantly associated with health care-seeking behavior in some or all five waves.

Table 4 presents the results of the regression analysis for the pooled logistic, random effects logistic, and fixed effects logistic models. The likelihood ratio test and Hausman's specification test showed highly significant test statistics ( $L R=569.63$ and $\left.\chi^{2}(24)=162.32\right)$. These results further demonstrated that the fixed effects logistic model should be preferred over the random effects logistic model. The results of the logistic regression analysis are shown in Table 4 as ORs. An OR greater than one indicated a positive effect on the likelihood of seeking health care, while an OR less than one indicated a negative effect.

Column (iii) of Table 4 presents factors affecting health care-seeking behavior using the fixed effects logistic model. Among those who reported physical discomfort, adults who currently smoked cigarettes were 0.65 times less likely to seek health care than those who formerly smoked (OR $=0.65,95 \% \mathrm{CI}: 0.50,0.84)$. Compared to nondrinkers, adults who regularly drank alcohol had a decreased likelihood of seeking health care $(\mathrm{OR}=0.77$, $95 \%$ CI: $0.65,0.91)$. Adults who never engaged in physical exercise had $24 \%$ lower odds of seeking healthcare than those who engaged in physical exercise $(\mathrm{OR}=0.76,95 \%$ CI: 0.69, 0.83).

Irrespective of the estimation method, adults who currently smoked cigarettes, regularly drank alcohol, and never engaged in physical exercise were less likely to seek health care when they felt physical discomfort (see Columns (i)- (iii) of Table 4).

\section{Discussion}

The current study examined the association between lifestyle factors and health care-seeking behavior among a Chinese adult general population using a five-wave longitudinal dataset. This study found that the proportion of individuals seeking health care increased from $68.8 \%$ in 2010 to $76.1 \%$ in 2018 . This result is not unexpected. Since the launch of the new health reform of 2009, the Chinese government has made considerable investments

Table 3 Lifestyle behaviors of adults who sought health care and those who did not seek health care

\begin{tabular}{|c|c|c|c|c|c|c|c|c|c|c|}
\hline & \multicolumn{2}{|l|}{2010} & & \multicolumn{2}{|l|}{2014} & \multicolumn{2}{|l|}{2016} & \multicolumn{2}{|l|}{2018} \\
\hline & \multicolumn{2}{|c|}{$N=8358$} & \multicolumn{2}{|c|}{$N=9061$} & \multicolumn{2}{|c|}{$N=8774$} & \multicolumn{2}{|c|}{$N=9021$} & \multicolumn{2}{|c|}{$N=9148$} \\
\hline & \multicolumn{2}{|c|}{$\overline{\text { Seeking health care }}$} & \multicolumn{2}{|c|}{$\overline{\text { Seeking health care }}$} & \multicolumn{2}{|c|}{$\overline{\text { Seeking health care }}$} & \multicolumn{2}{|c|}{ Seeking health care } & \multicolumn{2}{|c|}{$\begin{array}{l}\text { Seeking health } \\
\text { care }\end{array}$} \\
\hline & Yes & No & Yes & No & Yes & No & Yes & No & Yes & No \\
\hline \multicolumn{11}{|c|}{ Current smoking (\%) } \\
\hline Yes & 67.7 & 32.3 & 61.3 & 38.7 & 69.6 & 30.4 & 72.7 & 27.3 & 73.1 & 26.9 \\
\hline No & 69.2 & 30.8 & 67.0 & 33.0 & 73.3 & 26.7 & 75.7 & 24.3 & 77.1 & 22.9 \\
\hline$P$ value & 0.185 & & $<0.001$ & & 0.001 & & 0.005 & & $<0.00$ & \\
\hline \multicolumn{11}{|c|}{ Regular drinking (\%) } \\
\hline Yes & 62.3 & 37.7 & 57.0 & 43.1 & 64.9 & 35.1 & 69.7 & 30.3 & 69.8 & 30.2 \\
\hline No & 69.7 & 30.3 & 66.7 & 33.3 & 73.4 & 26.6 & 75.6 & 24.4 & 77.0 & 23.1 \\
\hline$P$ value & $<0.001$ & & $<0.001$ & & $<0.001$ & & $<0.001$ & & $<0.00$ & \\
\hline \multicolumn{11}{|c|}{ Physical inactivity (\%) } \\
\hline Yes & 68.7 & 31.3 & 65.5 & 34.5 & 71.8 & 28.2 & 74.2 & 25.8 & 74.2 & 25.8 \\
\hline No & 69.0 & 31.0 & 65.3 & 34.8 & 73.1 & 26.9 & 76.0 & 24.0 & 78.1 & 21.9 \\
\hline$P$ value & 0.795 & & 0.778 & & 0.204 & & 0.045 & & $<0.00$ & \\
\hline
\end{tabular}


Table 4 Logistic regression analysis of health care-seeking behavior

\begin{tabular}{|c|c|c|c|}
\hline & $\begin{array}{l}\text { Pooled logistic } \\
\text { (i) }\end{array}$ & $\begin{array}{l}\text { Random effects logistic } \\
\text { (ii) }\end{array}$ & $\begin{array}{l}\text { Fixed effects logistic } \\
\text { (iii) }\end{array}$ \\
\hline & Odds Ratios $(95 \% \mathrm{Cl})$ & Odds Ratios (95\% Cl) & Odds Ratios $(95 \% \mathrm{Cl})$ \\
\hline \multicolumn{4}{|l|}{ Smoking status } \\
\hline Current smoking & $0.84^{* * *}(0.75,0.93)$ & $0.79^{* * *}(0.69,0.89)$ & $0.65^{* * *}(0.50,0.84)$ \\
\hline Never smoking & $0.90^{*}(0.80,1.00)$ & $0.86^{* *}(0.75,0.98)$ & $0.79^{*}(0.60,1.04)$ \\
\hline \multicolumn{4}{|l|}{ Former smoking (ref.) } \\
\hline Regular drinking & $0.76^{* * *}(0.71,0.82)$ & $0.72^{* * *}(0.67,0.79)$ & $0.77^{* * *}(0.65,0.91)$ \\
\hline Physical inactivity & $0.76^{* * *}(0.72,0.79)$ & $0.73^{* * *}(0.69,0.77)$ & $0.76^{* * *}(0.69,0.83)$ \\
\hline \multicolumn{4}{|l|}{ Age group } \\
\hline \multicolumn{4}{|l|}{$16-24$ (ref.) } \\
\hline $25-64$ & $1.18^{* * *}(1.07,1.31)$ & $1.23^{* * *}(1.09,1.39)$ & $0.97(0.69,1.37)$ \\
\hline$>=65$ & $1.57^{* * *}(1.40,1.75)$ & $1.74^{* * *}(1.52,2.00)$ & $1.74^{* * *}(1.17,2.59)$ \\
\hline Male & $0.98(0.92,1.05)$ & $0.97(0.90,1.06)$ & $0.99(0.32,3.26)$ \\
\hline \multirow{2}{*}{\multicolumn{4}{|c|}{$\begin{array}{l}\text { Educational attainment } \\
\text { Illiteracy (ref.) }\end{array}$}} \\
\hline & & & \\
\hline Elementary school & $0.99(0.93,1.07)$ & $1.01(0.93,1.10)$ & $1.15(0.86,1.55)$ \\
\hline Middle school & $0.98(0.91,1.06)$ & $0.99(0.91,1.08)$ & $1.23(0.83,1.81)$ \\
\hline High school & $0.79^{* * *}(0.73,0.86)$ & $0.76^{* * *}(0.68,0.84)$ & $1.18(0.71,1.96)$ \\
\hline Above three-year college & $0.59^{* * *}(0.53,0.66)$ & $0.53^{* * *}(0.47,0.61)$ & $1.21(0.67,2.20)$ \\
\hline Married & $1.24^{* * *}(1.16,1.33)$ & $1.30^{* * *}(1.19,1.41)$ & $0.91(0.72,1.16)$ \\
\hline Urban residency & $0.83^{* * *}(0.79,0.88)$ & $0.80^{* * *}(0.75,0.86)$ & $1.25^{* *}(1.00,1.56)$ \\
\hline \multicolumn{4}{|l|}{ Medical insurance } \\
\hline GMI & $1.24^{* * *}(1.08,1.43)$ & $1.25^{* *}(1.05,1.48)$ & $1.01(0.74, .139)$ \\
\hline UEMI & $1.14^{* * *}(1.04,1.26)$ & $1.14^{* *}(1.01,1.27)$ & $1.08(0.87,1.35)$ \\
\hline URMI & $1.14^{* *}(1.03,1.27)$ & $1.17^{* *}(1.03,1.32)$ & $1.19(0.97,1.46)$ \\
\hline NRCMI & $1.51^{* * * *}(1.40,1.62)$ & $1.57^{* * *}(1.44,1.71)$ & $1.09(0.93,1.28)$ \\
\hline Other Insurance & $0.92(0.67,1.27)$ & $0.87(0.60,1.27)$ & $0.89(0.51,1.54)$ \\
\hline \multicolumn{4}{|l|}{ No Insurance (ref.) } \\
\hline Household income & $1.01^{* *}(1.00,1.01)$ & $1.01^{* * *}(1.00,1.01)$ & $1.01^{* *}(1.00,1.02)$ \\
\hline Economically active & $1.01(0.96,1.07)$ & $1.03(0.97,1.10)$ & $1.04(0.92,1.17)$ \\
\hline \multicolumn{4}{|l|}{ Health status } \\
\hline Poor & $1.38^{* * *}(1.29,1.47)$ & $1.46^{* * *}(1.36,1.58)$ & $1.42^{* * *}(1.26,1.59)$ \\
\hline \multicolumn{4}{|l|}{ Fair (ref.) } \\
\hline Good & $0.94^{* *}(0.89,0.99)$ & $0.94^{*}(0.88,1.00)$ & $1.04(0.93,1.16)$ \\
\hline Chronic conditions & $2.42^{* * *}(2.29,2.57)$ & $2.69^{* * *}(2.51,2.88)$ & $2.04^{* * *}(1.85,2.25)$ \\
\hline \multicolumn{4}{|l|}{ Severity of physical discomfort } \\
\hline Mild & $0.58^{* * *}(0.55,0.61)$ & $0.52^{* * *}(0.48,0.55)$ & $0.52^{* * *}(0.47,0.58)$ \\
\hline \multicolumn{4}{|l|}{ Moderate (ref.) } \\
\hline Serious & $1.87^{* * *}(1.76,1.98)$ & $2.09^{* * *}(1.95,2.24)$ & $1.94^{* * *}(1.75,2.15)$ \\
\hline Constant & $1.44^{* * *}(1.21,1.72)$ & $1.62^{* * *}(1.32,1.99)$ & \\
\hline Observations & 44,362 & 44,362 & 13,036 \\
\hline
\end{tabular}

Likelihood ratio test in random effects logistic model: $L R=569.63, p<0.001$

Hausman's specification test is significant at the $1 \%$ level: $X^{2}(24)=162.32, p<0.001$

Asterisks ${ }^{* * *}$ indicate statistical significance at the $1 \%$ level, ${ }^{* *}$ at the $5 \%$ level, and ${ }^{*}$ at the $10 \%$ level

in strengthening the accessibility and availability of health care facilities. As a result, almost every community (village) has at least one primary care facility. Moreover,
China successfully achieved near-universal health insurance coverage, with $95 \%$ of the population covered in 2011, and proposed a zero-profit drug policy, compelling 
public hospitals nationwide to sell drugs at cost without mark-up fees to make health care facilities more attractive to patients [19-21].

On the other hand, the proportion of people seeking health care in China is much higher than the findings in European studies. Elnegaard et al. [22] found that the proportion of the adult Danish population contacting a general practitioner with at least one symptom was $37 \%$. Elliott, McAteer, and Hannaford [23] reported that 20\% of respondents with symptoms consulted with a primary care health professional in the UK. Health care-seeking behavior in different countries may have been affected by degrees of access to care and levels of out-of-pocket payments. Both Demark and the UK have easy and free access to health care facilities. The gap in the proportion of people seeking health care may be because the formal referral system in China is now virtually absent. Patients have the freedom to choose any health care facilities they prefer to visit, regardless of their disease severity [24]. However, people with lifestyle behaviors including current smoking, regular drinking, and physical inactivity had a lower proportion of seeking health care in China.

A fixed effects logistic regression model was used to identify the lifestyle factors affecting health care-seeking behavior. The results indicate that among those who reported physical discomfort, adults who currently smoked cigarettes, regularly drank alcohol, and never engaged in physical exercise were less likely to seek health care. Similar results have been discovered in China, England, and Australia. For example, Zhou et al. [25] observed that physical inactivity decreased the probability of seeking health care in China. Smith et al. [12] found that smokers were less likely to seek help than nonsmokers in England. Feng et al. [13] revealed that people with multiple lifestyle factors, including smoking, alcohol consumption, diet and physical inactivity, were less likely to see general practitioners in Australia.

Four possible reasons may explain the inverse relationship between lifestyle factors and health care-seeking behavior. First, people with lifestyle behaviors including current smoking, regular drinking, and physical inactivity are more risk tolerant, and they may more willingly bear disease risk [26, 27]. A higher willingness to bear risk decreases the probability of seeking health care [28]. Second, lifestyle behaviors such as smoking, drinking, and physical inactivity, are linked with poor health conditions. People in poor health conditions are more likely to have negative experiences in the health care system and be less satisfied with it [29]. Lower patient satisfaction tends to decrease the probability of seeking health care [30]. Third, lifestyles result in chronic diseases, specifically heart disease, diabetes, and cancer [31]. People with lifestyle behaviors including current smoking, regular drinking, and physical inactivity may suffer from long-term chronic conditions and more than one chronic condition, which often leads to normalization of symptoms and thus inhibits health care seeking [32]. Last, lifestyle factors contribute to productive losses at work and reduced ability to work [33, 34]. People with lifestyle behaviors including current smoking, regular drinking, and physical inactivity may sacrifice some of their leisure time to perform unfinished work. Time constraints may delay some people from seeking health care [35].

Although the present study used a national survey to analyze the lifestyle factors affecting health care-seeking behavior among adults who reported physical discomfort, several limitations should be emphasized. First, the CFPS survey does not collect information on selfmedication practice, so this study defined health careseeking behavior as the seeking of professional help. Previous studies have shown that individuals who perceive themselves to have mild health problems are more likely to self-medicate in China [36, 37]. Second, data were obtained via a survey, and thus the limitations of all self-reported data such as recall bias and social desirability bias also apply here. Finally, although the present study adjusted for a large variety of control variables, it is possible that unknown or unmeasured confounders may explain the current findings.

\section{Conclusions}

This study estimated the effects of current smoking, regular drinking, and physical inactivity on health careseeking behavior among adults who reported physical discomfort in China. The empirical findings suggested that current smoking, regular drinking, and physical inactivity decreased the probability of seeking health care among adults who reported physical discomfort. Therefore, primary-level care should deliver screening and brief advice programs and pay more attention to those with lifestyle behaviors such as current smoking, regular drinking, and physical inactivity, thus avoiding missed opportunities to treat chronic conditions and detect new diseases early.

\section{Acknowledgments \\ The authors thank Zhengzhong Mao and Mariyam Suzana for the helpful comments.}

\section{Authors' contributions \\ JS designed the study and made important contributions to the revision of the manuscript. CL led the data analysis and wrote the manuscript. All authors read and approved the final manuscript. \\ Funding \\ This research was funded by the Inner Mongolia Medical University Health Economics Professionals Team, Scientific Research Starting Foundation for Doctoral Scholars in Inner Mongolia Medical University (YKD2019BSJJ008),}


and Scientific Research Projects in Higher Education Institutions in Inner Mongolia (NJSY20145).

\section{Availability of data and materials}

The datasets generated and/or analyzed during the current study are available in the Peking University Open Research Data Platform repository, https:// opendata.pku.edu.cn/dataset.xhtml?persistentld=doi:10.18170/DVN/45LCSO.

\section{Declarations}

\section{Ethics approval and consent to participate}

Permission and approval were obtained from the Peking University Biomedical Ethics Review Committee (IRB00001052-14010). All methods were carried out in accordance with relevant guidelines and regulations.

\section{Consent for publication}

No applicable.

\section{Competing interests}

The authors declare that they have no competing interests.

\section{Received: 1 February 2021 Accepted: 30 December 2021}

Published online: 10 January 2022

\section{References}

1. The Chinese National Health Commission. The Nutrtion and Chronic Disease of the Chinese Population (2015). Available online: http://www. nhc.gov.cn/jkj/s5879/201506/4505528e65f3460fb88685081ff158a2.shtml (Accessed on 15 Oct. 2020).

2. Wang $L$, Kong $L, W u F$, Bai $Y$, Burton R. Preventing chronic diseases in China. Lancet. 2005;366(9499):1821-4.

3. Steyn K, Damasceno A. Lifestyle and related risk factors for chronic diseases. Dis Mortal Sub-Saharan Africa. 2006:2:247-65.

4. WHO, Global Adult Tobacco Survey (GATS). Fact sheet China 2018. Available online: https://www.who.int/docs/default-source/wpro-docum ents/countries/china/2018-gats-china-factsheet-cn-en.pdf?sfvrsn=3f4e2 da9_2 (Accessed on 16 Oct. 2020)

5. Wagner EH, Curry SJ, Grothaus L, Saunders KW, McBride CM. The impact of smoking and quitting on health care use. Arch Intern Med. 1995;155(16):1789-95.

6. Sturm R, An R, Maroba J, Patel D. The effects of obesity, smoking, and excessive alcohol intake on healthcare expenditure in a comprehensive medical scheme. S Afr Med J. 2013;103(11):840-4.

7. Wacker M, Holle R, Heinrich J, Ladwig KH, Peters A, Leidl R, et al. The association of smoking status with healthcare utilisation, productivity loss and resulting costs: results from the population-based KORA F4 study. BMC Health Serv Res. 2013;13(1):278.

8. Kahende JW, Adhikari B, Maurice E, Rock V, Malarcher A. Disparities in health care utilization by smoking status-NHANES 1999-2004. Int J Environ Res Publich Health. 2009;6(3):1095-106.

9. Kraft AD, Quimbo SA, Solon O, Shimkhada R, Florentino J, Peabody JW. The health and cost impact of care delay and the experimental impact of insurance on reducing delays. J Pediatr. 2009;155(2):281-5.

10. Chen J, Rizzo JA, Rodriguez HP. The health effects of cost-related treatment delays. Am J Med Qual. 2011:26(4):261-71.

11. Thomas AW, Valero-Elizondo J, Khera R, Warraich HJ, Krumholz HM, Nasir $\mathrm{K}$, et al. Foregone and delayed medical care is associated with increased health care costs and utilization among heart failure patients in the United States. Circulation. 2019;140(Suppl_1):A13991.

12. Smith CF, Whitaker K, Winstanley K, Wardle J. Smokers are less likely than non-smokers to seek help for a lung cancer'alarm'symptom. Thorax. 2016;71(7):659-61.

13. Feng $X$, Girosi F, McRae IS. People with multiple unhealthy lifestyles are less likely to consult primary healthcare. BMC Fam Pract. 2014;15(1):1-7.

14. Xie Y, Lu P. The sampling design of the China family panel studies (CFPS). Chin J Sociol. 2015:1(4):471-84.
15. Xie Y, Zhang X, Tu P, Ren Q, Sun Y, Lv P, et al. China family panel studies user's manual. 3rd ed. Beijing: Institute of Social Science Survey, Peking University; 2017.

16. Xie Y, Hu J. An introduction to the China family panel studies (CFPS). Chin Sociol Rev. 2014;47(1):3-29.

17. Andreß HJ, Golsch K, Schmidt AW. Applied panel data analysis for economicand social surveys: Springer Science \& Business Media; 2013.

18. Greene WH. Econometric analysis: Pearson Education India; 2003.

19. Ta Y, Zhu Y, Fu H. Trends in access to health services, financial protection and satisfaction between 2010 and 2016: has China achieved the goals of its health system reform? Soc Sci Med. 2020;245:112715.

20. Li L, Fu H. China's health care system reform: Progress and prospects. Int J Health Plann Manag. 2017:32:240-53.

21. Du J, Xie J, Qian Y, Wu M, Huang W, Yin J, et al. Impact of China's zero mark-up drug policy on drug cost of NCDs' outpatients: an interrupted time series analysis. BMC Health Serv Res. 2021;21:404.

22. Elnegaard S, Andersen RS, Pedersen AF, Larsen PV, Søndergaard J, Rasmussen S, et al. Self-reported symptoms and healthcare seeking in the general population-exploring "the symptom iceberg". BMC Public Health. 2015;15:1-11.

23. Elliott AM, McAteer A, Hannaford PC. Revisiting the symptom iceberg in today's primary care: results from a UK population survey. BMC Fam Pract. 2011:12:1-11.

24. Eggleston K, Ling L, Qingyue M, Lindelow M, Wagstaff A. Health service delivery in China: a literature review. Health Econ. 2008;17(2):149-65.

25. Zhou J, Xu J, Zhang J, Duan Z. Effect of physical activity on healthcare seeking behavior in the general Chinese population: an urban-rural perspective. Glob Health J. 2020;4(3):107-12.

26. Khwaja A, Sloan F, Salm M. Evidence on preferences and subjective beliefs of risk takers: the case of smokers. Int J Ind Organ. 2006;24(4):667-82.

27. Dave D, Saffer H. Alcohol demand and risk preference. J Econ Psychol. 2008;29(6):810-31.

28. Lutter JI, Szentes B, Wacker ME, Winter J, Wichert S, Peters A, et al. Are health risk attitude and general risk attitude associated with healthcare utilization, costs and working ability? Results from the German KORA FF4 cohort study. Health Econ Rev. 2019;9(1):26.

29. Kim AM, Bae J, Kang S, Kim YY, Lee JS. Patient factors that affect trust in physicians: a cross-sectional study. BMC Fam Pract. 2018;19(1):187.

30. Fenton JJ, Jerant AF, Bertakis KD, Franks P. The cost of satisfaction: a national study of patient satisfaction, health care utilization, expenditures, and mortality. Arch Intern Med. 2012;172(5):405-11.

31. Al-Maskari F. Lifestyle diseases: an economic burden on the health services, UN chronicle. The Magazine of the United Nations; 2010. Available at: https://www.un.org/en/chronicle/article/lifestyle-diseases-economicburden-health-services.

32. Galdas PM, Cheater F, Marshall P. Men and health help-seeking behaviour: literature review. J Adv Nurs. 2005:49(6):616-23.

33. Robroek SJ, van den Berg TI, Plat JF, Burdorf A. The role of obesity and lifestyle behaviours in a productive workforce. Occup Environ Med. 2011;68(2):134-9.

34. Rongen A, Robroek SJ, van Lenthe FJ, Burdorf A. Workplace health promotion: a meta-analysis of effectiveness. Am J Prev Med. 2013;44(4):406-15.

35. Taber JM, Leyva B, Persoskie A. Why do people avoid medical care? A qualitative study using national data. J Gen Intern Med. 2015;30(3):290-7.

36. Lei $X$, Jiang H, Liu C, Ferrier A, Mugavin J. Self-medication practice and associated factors among residents in Wuhan, China. Int J Environ Res Publich Health. 2018;15(1):68.

37. Li YF, Rao KQ, Ren XW. Use of and factors associated with self-treatment in China. BMC Public Health. 2012;12(1):995.

\section{Publisher's Note}

Springer Nature remains neutral with regard to jurisdictional claims in published maps and institutional affiliations. 